\title{
Idea Generation and Brainstorming Under the Aspect of the New Groupthink - The Differences Between Extraverts and Introverts
}

\author{
Oliver Mauroner \\ University of Applied Sciences Mainz
}

\author{
Lara Zschau \\ Mercer Promerit AG
}

Working in collaborative groups and teams now represents the practice predominantly adopted by organizations aspiring to create innovation. However, this trend towards boundless collaboration at work is harshly criticized for a resulting discrimination of introverted employees - called the New Groupthink. According to this, introverts suffer from working conditions that inhibit individual and quiet work. The current shift towards collaboration overall elicits lower creativity and achievement levels due to the resulting suppression of introverts. This inefficiency hence depicts a relevant issue for companies by reason of creativity and innovation's decisive stake in todays' turbulent environments. Therefore, this quantitative research investigates whether hybrid brainstorming can equate introverts with extraverts by balancing their idea contribution. It suggests solutions to both introverts, with regards to enhancing their stake in ideation, and companies, with regards to how to apply ideation methods in most efficient ways.

Keywords: new groupthink, brainstorming, creativity, ideation, introverts vs. extroverts

\section{INTRODUCTION}

Today, increasingly globalized competition, new possibilities for production, as well as fast-paced technological developments jointly force companies to find strategies to assure their competitive advantage and long-term survival. Resulting therefrom, creativity and innovation have become central areas of interest as well as key success factors (Anderson, Potočnik, \& Zhou, 2014; Tang, 2016). In this context, working in collaborative teams now represents the practice predominantly adopted by organizations aspiring to remain competitive (Korde \& Paulus, 2017). However, this trend towards boundless collaboration at work is harshly criticized by a theory called the "New Groupthink", which argues for a resulting discrimination of introverted employees (Cain, 2012, 2013). According to this perspective, introverts suffer from working conditions that inhibit individual and quiet work. The theory consequently argues that the current shift towards limitless collaboration overall elicits lower creativity and achievement levels due to the resulting suppression of introverts (Cain, 2013). In this regard, another focus of criticism is the most widely applied collaborative ideation method of group brainstorming. Since this prominent method normally does not allow for individual and quiet ideation, introverts are supposed to fall behind extraverts in this form of idea generation. The application of traditional group brainstorming was effectively found to bear several shortcomings that can be ascribed to multiple factors (Diehl \& Stroebe, 1987, 1991; Lamm \& Trommsdorff, 
1973; Mullen, Johnson, \& Salas, 1991; Paulus, Larey, \& Ortega, 1995; Rietzschel, Nijstad, \& Stroebe, 2006). Indeed, one of the factors that cause restriction, constitutes the factor of participants' personalities, although it has only sparsely been scientifically explored so far (Callaghan, 2009; Camacho \& Paulus, 1995; Furnham \& Yazdanpanahi, 1995; Jung, Lee, \& Karsten, 2012). In particular, earlier research accredited variations in performance levels of introverts and extraverts by indicating that introverts generally tend to fall behind extraverts with regards to idea generation in traditional group brainstorming (Bradshaw, Stasson, \& Alexander, 1999; Callaghan, 2009; Camacho \& Paulus, 1995). This finding consequently supports the claims made by the "New Groupthink" theory. However, existing research on the actual impact that limitless collaboration has on introverted employees is limited and so are findings on the impact of personality differences in brainstorming. Accordingly, by now there do not exist any solutions for closing the performance gap between introverts and extraverts in brainstorming.

Although this problem has yet to be scientifically approached, there are some indications for potential solutions. One flexible method, namely hybrid brainstorming, that consists of an alternation between individual and group brainstorming, was already shown to possess the power to enhance overall brainstorming performance (Korde \& Paulus, 2017). Since introverts were generally found to prefer quiet ideation time (Callaghan, 2009; Culp \& Smith, 2005), an alternating brainstorming method could be favourable to their performance. However, no research has yet investigated whether hybrid brainstorming helps to overcome the discrepancy between introverts' and extraverts' contributions in group brainstorming. Therefore, the fundamental aim of this research is to ascertain whether hybrid brainstorming can empower introverts in brainstorming by balancing the idea contribution of introverts and extraverts.

This paper is structured as follows. Chapter 2 will review the existing body of literature, which serves as the theoretical framework for this research. It concludes with the concept of hybrid brainstorming and a derivation of hypotheses. Subsequently, chapter 3 will introduce the methodological approach selected in this research. Next, chapter 4 encompasses the depiction of the obtained results and an outline of the hypotheses tests. In this turn, the fundamental research question is answered. Finally, chapter 5 includes a discussion of the results and chapter 6 contains the study's overall conclusions and its major limitations, implications and recommendations for further research.

\section{THEORETICAL BACKGROUND}

\section{Collaborative Creativity and the "New Groupthink"}

Business and society are experiencing a shift from the "Information Age" towards the "Creativity Age", where economies classify "creativity" as their core characteristic and the production of ideas is valued over that of things (Dubina, Carayannis, \& Campbell, 2012). For these reasons, creativity and innovation are moving into the center of organizational settings and are increasingly seen as vital for organizational performance, competitive advantage, and long-term survival (Anderson et al., 2014; Mumford, Hester, \& Robledo, 2012; Tang, 2016; West, 2002). One widely-adopted approach in this regard is to refrain from rigid, hierarchical structures and move towards more organic and flexible organizational forms. In doing so, the team rather than the individual becomes the basic building block of companies and collaboration moves in the center of work (Tjosvold, West, \& Smith, 2003). Recent management literature places its major focus on collaborative forms of creativity and promotes the establishing of teamwork with regard to innovation (Anderson et al., 2014; Hülsheger, Anderson, \& Salgado, 2009; Kozlowski \& Ilgen, 2006). Group work is seen to increase the effectiveness of the growingly complex organizations and the adaptability to their fast-changing environments.

However, this all-encompassing, dominating thought of collaboration is not without controversy. Likewise, the continuing development towards boundless collaboration in every aspect of work is criticized as being counterproductive for introverted employees, i.e. for individuals who oftentimes enjoy solitude, need to consider ideas individually before discussing them in groups, and prefer depth over superficiality (Dossey, 2016). (Cain, 2012, 2013) argues against the rising notion of collaboration being the sole key to creativity and innovation. In this regard, she criticizes the elevation of teamwork above everything else, as well as the widespread belief that exclusively gregarious places allow for creativity to take place. Cain 
(2013) raises concern over the effectiveness of today's development towards compelled collaboration by calling this phenomenon the "New Groupthink". According to Jung's publication "Psychological Types" (1921, reprinted 2017), Cain (2013) characterizes introverts as individuals drawn to their inner world, who try to make meaning of the happenings around them and who reenergize through solitude. Other publications confirm these arguments, where introverts are oftentimes described as quiet, reserved, retiring, shy, silent, and with-drawn (Culp \& Smith, 2005; McCrae \& John, 1992). Furthermore, introverts oftentimes show higher creativity levels compared to extraverts (Feist, 1998). However, this argument is not universally valid. In fact, findings on the creative personality revealed that creative people can be both extraverted and introverted (Eysenck, 1995). Studies with reference to the widely-adopted five-factor model of personality (Goldberg, 1990) found that individuals high on openness to experience and low on conscientiousness, are the most creative (Batey, Chamorro-Premuzic, \& Furnham, 2010). Since both factors represent subscales of the introversion-extraversion scale, introversion cannot be a reliable indicator for creativity by default. However, based on the former characterization of introverts and findings on their creativity levels, Cain (2013) conclusively argues that introverts need silence and privacy to perform at their best and therefore claims that solitude can be a vital key to creativity. In her point of view, "collaboration kills creativity" (Cain, 2013, p. 71); resulting therefrom, she proposes to find the right balance and to create conditions that allows both for individual and group work.

Existent studies indicate poor performances when using group brainstorming (Dunnette, Campbell, \& Jaastad, 1963; Furnham, 2000), showing that group brainstorming lacks effectivity. One reason might be the fear of judgement by others, also known as evaluation apprehension (Diehl \& Stroebe, 1987). Dossey (2016, p. 157) also calls for more individual work in ideation phases by stating that "brainstorming is an extroverted strategy par excellence". He argues that in order to understand the inefficiencies of group brainstorming, one has to understand the differences between introverts and extraverts. However, none of the authors conducted own research to legitimate their arguments.

\section{Advantages and Inefficiencies of Brainstorming}

Brainstorming is regarded as the most commonly adopted approach for generating creative ideas and maintains widespread acceptance (Rietzschel et al., 2006). In this regard, it is generally assumed that sharing ideas in groups increases both the number and novelty of ideas generated (Korde \& Paulus, 2017). Brainstorming can correspondingly be defined as a "problem solving technique that involves the spontaneous distribution of ideas from all members of a group" (Furnham, 2000, p. 23). Its underlying purpose is to produce as many different ideas as possible, while relieving participants from inhibition, selfcriticism, and criticism by third persons (Taylor, Berry and Block, 1958). The method was first introduced by Osborn (1957, reprinted 2013), who argued for its outstanding effectiveness in terms of quantity and quality of ideas generated, compared with individual thinking. He introduced four basic rules that characterize the traditional-, interactive group brainstorming method (called "traditional group brainstorming" hereafter), namely (1) any criticism is ruled out, (2) lateral thinking is welcomed, (3) quantity is wanted, and (4) combinations and improvements of ideas are sought.

Nonetheless, Osborn did not scientifically prove the method's effectiveness (Henningsen \& Henningsen, 2013). Notwithstanding, there are scholars who found brainstorming to be an important source of creativity and underpin its positive effects on performance outcomes. To illustrate, Paulus (2000), discovered that a certain extent of excitement and synergy, which is commonly present during brainstorming, can facilitate idea generation. Further advantages are social and cognitive stimulation, since participants benefit from mutual stimulation of associations that go beyond individual imagination. However, it is assumed that exclusively under certain conditions can idea sharing in groups be productive. Only if participants pay attention, i.e. follow their colleagues as well as incubate and reflect on ideas, can the idea exchange process in groups lead to enhanced performance (Heslin, 2009; Paulus \& Yang, 2000). Furthermore, Sutton and Hargadon (1996) demonstrated that the use of traditional group brainstorming can have positive effects on organizations that go beyond classic measures of productivity, such as the quantity of ideas. In this regard, also an increase in group cohesiveness can be observed over time within 
brainstorming groups, which is believed to bring about socioemotional advantages to the organization (Henningsen \& Henningsen, 2013).

On the contrary, a number of scholars found traditional group brainstorming to be less productive in comparison to an equal number of individuals brainstorming alone, so-called nominal groups, and consequently raise concern over its widespread utilization. Taylor, Berry and Block (1958) were the first authors to demonstrate that nominal brainstorming groups outperform interactive groups in terms of the number of ideas generated. By means of an experiment comparing both types of brainstorming groups, they concluded that "group participation when using brainstorming inhibits creative thinking" (Taylor et al., 1958, p. 43). Ever since, multiple researchers replicated the finding of interactive brainstorming groups being less productive in terms of both quantitative and qualitative measures, compared to nominal groups (Diehl \& Stroebe, 1987, 1991; Lamm \& Trommsdorff, 1973; Mullen et al., 1991; Paulus et al., 1995; Rietzschel et al., 2006). Despite all evidence for its ineffectiveness, traditional group brainstorming persists in being a commonly used practice and popular method for idea generation in organizations (Callaghan, 2009). As a result, a central issue in brainstorming literature has been the identification of factors that inhibit the performance in interactive brainstorming groups (Camacho \& Paulus, 1995). Three of these are primarily discussed, namely (1) social loafing, i.e. some individuals rest while others do the work, (2) production blocking, i.e. only one person is able to talk at a time and (3) evaluation apprehension, i.e. the fear to disgrace oneself in front of group members (Diehl \& Stroebe, 1987). Referring to recent literature, Paulus, Dzindolet and Kohn (2012) underpin that psychological or participative safety as well as cohesion and trust are factors that influence general team creativity.

\section{Personality and Brainstorming}

Personality traits are defined as "consistent patterns in the way individuals behave, feel, and think" (Pervin \& Cervone, 2010, p. 228). The scholarly field on personality traits is approaching consensus on a general taxonomy, namely the "Big Five" personality dimensions. This model represents a common framework of diverse perspectives (John \& Srivastava, 2001). One of the model's dimensions is the personality trait of extraversion (McCrae \& John, 1992). As a higher-order personality trait, it is composed of several more specific traits and can be understood as a broad continuum that reflects the dimension of individual differences, ranging from introversion to extraversion (Watson \& Clark, 2007). Basically, it can be interpreted as the general level of sociability. Individuals who are high in extraversion, were found to be active, assertive, energetic, enthusiastic, outgoing and talkative, whereas individuals low in extraversion are rather quiet, reserved, retiring, shy, silent, and withdrawn (McCrae \& John, 1992). In addition, extraverts prefer to generate ideas in groups and express their thoughts in front of others, while introverts excel when they have quiet time to think things through and process their thoughts before speaking (Culp \& Smith, 2005).

Since individual personality was found to affect team creativity, the factor of personality increasingly gained significance within the brainstorming literature (Hoff, Carlsson, \& Smith, 2012; Paulus et al., 2012). However, to date, only a comparatively small body of research concerning the connection between personality and brainstorming performance is available (Callaghan, 2009; Camacho \& Paulus, 1995; Furnham \& Yazdanpanahi, 1995; Jung et al., 2012). Goup members' personalities generally affect the overall group performance by influencing individual creativity levels and thinking styles (Bolin \& Neuman, 2006; Hoff et al., 2012; Jung et al., 2012). Primarily, introverts seem to produce fewer ideas when compared to extraverts in traditional group brainstorming. Callaghan (2009), for instance, conducted an experiment with undergraduate students exploring the connection between brainstorming performance and personality type in cross functional, new product development teams. By means of the MBTI ${ }^{\circledR}$ personality test (Briggs Myers, 1995), she found that introverts were generally less involved than extraverts in brainstorming rounds. This agrees with Dossey (2016), who affirms that when involved in group idea-generation, introverts usually fall behind extraverts regarding idea expression. Other research (Aguilar-Alonso, 1996; Jung et al., 2012) reinforces this finding by confirming significant performance differences between extraverts and introverts in terms of unique and diverse ideas. In accordance, Bradshaw et al. (1999) demonstrated that one single introverted group member leads to lower productivity and increased evaluation 
apprehension. Camacho and Paulus (1995) were the first scholars to indicate that individual differences could actually be accountable for the performance gap between nominal and interactive brainstorming groups. This underpins Dossey's (2016) opinion that in order to understand the reasons for brainstorming inefficiencies, one has to understand the differences between introverts and extraverts. Taken as a whole, the findings point to the critical conclusion that the involvement of introverted group members in traditional group brainstorming entails productivity impairment. However, no research has yet to find ways to empower introverts in group brainstorming and therewith enhance overall productivity.

Therefore, the following is hypothesized (H1): In traditional interactive group brainstorming, introverted group members contribute significantly less to the total amount of ideas generated, compared to extraverted group members.

\section{Development of Hybrid Brainstorming}

Apart from investigating the factor of personality, some authors have already discovered brainstorming methods which generally help to bridge the performance gap between interactive and nominal brainstorming groups. Still, no research has proved these methods to overcome the inequalities in brainstorming performance between introverts and extraverts. First, there is the so-called "brainwriting" method, which is "the silent, written generation of ideas by a group of people" (VanGundy, 1984, p. 68). This method entails several forms and can overcome various inefficiencies such as minimizing status differences between participants. Furthermore, research has revealed that it leads to superior idea generation compared with both non-sharing or nominal brainstorming groups (Paulus \& Yang, 2000). Nevertheless, social interaction and active discussions are oftentimes critical for group success, which is why brainwriting cannot always be selected as an alternative to interactive group brainstorming (VanGundy, 1984). Second, there is the method of electronic brainstorming, which is an "e-collaboration method that employs networked computer terminals and software designed to allow group members to communicate electronically during idea generation exercises" (DeRosa, Smith, \& Hantula, 2007, p. 1550). On the one hand, electronic brainstorming was found to both increase productivity and satisfaction with the interaction process compared with traditional face-to-face brainstorming. On the other hand, overall benefits of this method were found to be limited and electronic brainstorming groups had to consist of more than 7 people to outperform nominal groups (DeRosa et al., 2007). Besides, the synergistic effect of group collaboration was missing, which made the method unsuitable to apply universally (Korde \& Paulus, 2017). Third, the so-called "hybrid brainstorming" method, which combines individual and group brainstorming phases by switching between individual brainwriting and group brainstorming. This method was likewise found to overcome several productivity barriers and enhance the overall effectivity of the brainstorming process (Korde \& Paulus, 2017). Some early findings have already indicated that an alternation between the conditions makes sense and therewith provided fist hints concerning the method's advantages over traditional group brainstorming. In fact, Osborn (1957, reprinted 2013) already noted that an alternation between group and individual ideation has the power to produce maximum results, although not empirically verifying his argument. Subsequently, several studies suggested that the exposure to other persons' ideas may enhance brainstorming performance (Jung et al., 2012). Likewise, Paulus et al. (1995) stated that "group brainstorming may be most useful after individuals have generated ideas individually for a period of time and need the additional social stimulation" (p. 252). Girotra, Terwiesch and Ulrich (2010) conducted an experiment to asses two brainstorming conditions, namely a group and a hybrid condition, where individuals initially brainstormed alone and then together. The authors found strong support that the best ideas generated in the hybrid condition were better than those generated in the group condition. Besides, the hybrid groups generated three times as many ideas as the traditional groups. Accordingly, Korde (2014) conducted studies to achieve better performance by means of hybrid brainwriting methods. She found that the hybrid condition outperformed the traditional group condition. The most recent experiment by Korde and Paulus (2017) once again demonstrated the benefits of hybrid brainwriting compared to alone and group brainwriting reflected in the number of ideas generated. Still, these findings of Korde and Paulus (2014; 
2017) are exclusively valid for the hybrid brainwriting method, which does not involve interactive group discussions, but brainwriting as such.

\section{Personality and Hybrid Brainstorming}

Since hybrid brainstorming was found to narrow the general productivity gap between nominal and interactive brainstorming groups, it can be questioned whether this method likewise helps overcome the performance gap between introverts and extraverts in group brainstorming. However, hardly any studies have investigated the effect of personality type on hybrid brainstorming to date. Nevertheless, some of the studies previously discussed, provide first hints that hybrid brainstorming could be favourable for introverts' enhanced contribution to ideation. Camacho and Paulus (1995) have indicated that interactive group brainstorming would be best suited for individuals low in social anxiety since introverts might be too concerned about the reactions of others. Correspondingly, evaluation apprehension, i.e. the fear to disgrace oneself in front of other group members, has been identified as one major factor inhibiting brainstorming performance early on (Diehl \& Stroebe, 1987). Furthermore, it was found that the minor performance in interactive brainstorming groups can be assigned to differences in personality types (Camacho \& Paulus, 1995), mainly due to the underperformance of introverts. Since introverts usually prefer to think quietly before talking, e.g. reaching conclusions before discussing their thoughts, and need time to recharge their energy (Callaghan, 2009; Culp \& Smith, 2005), an alternating brainstorming process could be favourable to their performance.

\section{Based thereupon, the following is hypothesized (H2): In hybrid brainstorming, introverted group members contribute significantly more to the total amount of ideas generated, compared to traditional interactive group brainstorming.}

Furthermore, Korde (2014) strived to investigate the general increase in performance in hybrid brainwriting. Hence, she hypothesized that participants high in extraversion will generate the most ideas within the hybrid condition. However, this hypothesis was not supported, even though the hybrid method did yield an increase in overall brainstorming performance. Since extraverts do not necessarily exhibit an increased performance in hybrid conditions, the increase in overall performance could be ascribed to the improved performance of introverts. This could implicate that extraverts do not fundamentally perform in a superior manner, but that the brainstorming method as such causes the performance gap between the personality types. If hybrid brainstorming can overcome this gap, the contributions of extraverts and introverts should converge accordingly. A similar effect was noted by Camacho and Paulus (1995) for the general productivity gap between nominal and real groups in brainstorming.

\section{Therefore, the following hypothesis (H3) is stated: In hybrid brainstorming, introverted and extraverted group members contribute equal shares to the total amount of ideas generated}

In addition, Korde and Paulus (2017) have already established that the order of individual and group phases in hybrid brainstorming is of minor significance to the outcome. However, neither has a study investigated the effect of the number of changes between the two conditions nor its impact on the performance of introverts compared to extraverts. Some studies on hybrid brainstorming have utilized one individual and one group phase (Girotra et al., 2010; Paulus, Larey, \& Dzindolet, 2000; Paulus et al., 2015), others employed experimental designs with two aligned sequences of individual and group phases, i.e. four phases per group (Korde, 2014; Korde \& Paulus, 2017). However, these scholars did not argue for the number of switches between the two conditions. Nevertheless, the general exposure to the ideas of others can lead to an overall increase in ideas generated (Paulus et al., 2015). In this regard, it was shown that individual reflection after group discussion leads to associations and the further development of others' ideas (Paulus et al., 2015; Paulus \& Yang, 2000). On the contrary, if phases last too long or if only brainstorming as a group without individual phases, a steady decline of generated ideas can be observed 
(Korde \& Paulus, 2017). Besides, Kasof (1997) argued that introverts have a narrower attention span than extraverts. Therefore, the involvement of frequent individual phases allows them to recharge their energy for subsequent group discussion.

Hence, the following is hypothesized (H4): In hybrid brainstorming, introverted group members contribute significantly more ideas if frequent changes between individual and group phases are included, compared to less frequent changes.

\section{Individual Satisfaction in Hybrid Brainstorming}

Although satisfaction was found to be an important factor for understanding overall brainstorming performance, metrics in brainstorming experiments oftentimes exclusively focus on the quantity of ideas generated (Bolin \& Neuman, 2006; Callaghan, 2009). However, despite all scientifically proven inefficiencies, the general satisfaction with brainstorming remains repeatedly named as one reason for its widespread utilization. In fact, people seem to enjoy brainstorming, since it satisfies their need for social interaction (Heslin, 2009; Paulus, 2000). Besides, group brainstorming leads to more favourable perceptions of individual performance (Paulus et al., 2000). However, hardly any studies have investigated satisfaction levels of introverts compared to extraverts after traditional group brainstorming or hybrid brainstorming. Callaghan (2009) conducted one of the rare studies exploring satisfaction levels of introverts and extraverts, although she did not involve any hybrid methods. In two out of three brainstorming sessions, a lower satisfaction level was measured for introverts. The only case in which introverts reported a slightly higher satisfaction level compared to extraverts, involved a brainstorming method that allowed introverts to think longer and to be introspective.

Based thereupon, the following is hypothesized (H5): Introverted group members show a lower satisfaction-level after traditional interactive group brainstorming compared to extraverted group members.

As already stated above, no study has investigated participants' satisfaction after hybrid brainstorming rounds, regarding their personality type. However, since hybrid brainstorming entails individual reflection phases, it can be assumed that introverts enjoy hybrid brainstorming over traditional group brainstorming. This is underlined by their general preference of having quiet time to think things through (Culp \& Smith, 2005). Callaghan's finding (2009) that a method which allows introverts to think more leads to increased satisfaction levels, already provides a first hint that introverts may prefer hybrid brainstorming over traditional methods.

Accordingly, the following is hypothesized (H6): Introverted group members show a higher satisfaction-level after hybrid brainstorming compared to traditional brainstorming.

\section{METHODOLOGY}

\section{Research Methodology}

This research is of quantitative nature, following a deductive approach while testing 6 hypotheses (H1H6) that were derived from prior scientific findings. Accordingly, the research is based upon the fundamental philosophy of postpositivism, common for experimental designs and surveys. This perspective holds that causes determine certain effects or outcomes (Creswell, 2008). In this research, a relationship between the independent variables (IV) personality type and brainstorming methods and the dependent variables (DV) brainstorming outcome and post brainstorming satisfaction is advanced in form of hypotheses.

The methodology of this thesis consists of two elements. In the first instance, the underlying research methodology is an experimental design for testing the hypotheses H1-H4. This method entails "manipulating levels or amounts of selected independent variables (causes) to examine their influence on 
dependent variables (effects)" (Brown \& Melamed, 1990, p. 1). Such causal conclusions can be drawn most appropriately within experimental research, since variables other than the variables of interest, are controlled (Kirk, 2013). In the case of this research, the influence of personality types (introverted, extraverted) and selected brainstorming methods (traditional group brainstorming and two hybrid brainstorming methods) on the outcome of brainstorming, will be investigated. Since the impact of changes in two causes, i.e. personality type and brainstorming methods, are explored, this research employs a factorial design (Gray, 2004). Selfsame methodology is well-suited for such research since it allows to test the hypothesized relationship between personality type and brainstorming method on brainstorming outcome while controlling for nuisance variables (Kirk, 2013). Besides, scholars who conducted previous studies that investigated the relationship between brainstorming and personality types, likewise applied the methodological approach of experiments (Bolin \& Neuman, 2006; Callaghan, 2009; Furnham \& Yazdanpanahi, 1995; Jung et al., 2012; Korde \& Paulus, 2017). By these means, the results of this research can directly be compared to and be discussed in light of earlier findings as laid out in chapter 2 .

In addition, a second methodological element in form of a survey is utilized to test the hypotheses H5H6. This methodology involves a systematic, highly standardized collection of data by means of data collection methods, such as questionnaires (Sapsford, 2007). These characteristics allow a statistical analysis of survey data, suitable for quantitative research. The conducted survey aims at measuring and comparing satisfaction levels of introverted and extraverted participants after each brainstorming round. Previously conducted studies have chosen the same methodological approach, such as Korde (2014) or Camacho and Paulus (1995).

\section{Sample}

The sample of the present study consisted of business students from Germany, which were selected by applying a convenience sampling method (Quinlan, 2011). The total sample hence consisted of 87 participants, whereof 54 were male and 30 were female students; three participants did not indicate their gender. The age ranged from 19 to 32 years, with a mean of 22 years. During the course of the study, the sample was divided into three subsets: (1) introverted participants $(\mathrm{N}=16),(2)$ extraverted participants $(\mathrm{N}$ $=46)$ and (3) average participants $(\mathrm{N}=25)$, i.e. participants that rather fall into the middle of both personality types and could not be assigned to one of them. To include those participants classified as average in the later statistical analysis could have falsified the results, as they do not show distinct enough extraverted or introverted behaviour. Therefore, these participants were not taken into consideration (see table 1 for descriptive sample data).

TABLE 1

\section{DESCRIPTIVE SAMPLE DATA}

\begin{tabular}{|c|c|c|c|c|c|c|}
\hline & & Male & Female & Not indicated & Sum & \\
\hline \multirow[t]{4}{*}{ Introverted } & Day 1 & 3 & 1 & 1 & 5 & \\
\hline & Day 2 & 4 & 3 & - & 7 & \\
\hline & Day 3 & 2 & 2 & - & 4 & \\
\hline & Sum & 9 & 6 & 1 & & 16 \\
\hline \multirow[t]{4}{*}{ Extraverted } & Day 1 & 8 & 5 & - & 13 & \\
\hline & Day 2 & 11 & 8 & 2 & 21 & \\
\hline & Day 3 & 8 & 4 & - & 12 & \\
\hline & Sum & 27 & 17 & 2 & & 46 \\
\hline \multirow[t]{4}{*}{ Average } & Day 1 & 3 & 2 & - & 5 & \\
\hline & Day 2 & 7 & 5 & - & 12 & \\
\hline & Day 3 & 8 & 0 & - & 8 & \\
\hline & Sum & 18 & 7 & - & & 25 \\
\hline Sum & & 54 & 30 & 3 & & 87 \\
\hline
\end{tabular}


Based on their personality type, the participants were randomly divided in a total of 23 brainstorming groups. A general group size of four was chosen because previous studies have chosen the same size (Bolin \& Neuman, 2006; Henningsen \& Henningsen, 2013). However, two groups consisted of three participants only, whereof one was subject of subsequent analysis. The reason for their exclusion is that seven of the 23 brainstorming groups consisted of students classified as average within the personality test and were not taken into consideration. All remaining brainstorming groups were formed of one participant classified as introverted and two to three participants classified as extraverted. Conclusively, 62 participants (16 introverted, 46 extraverted), equalling 16 brainstorming groups, were taken into consideration for analysis.

\section{Measures and Instrumentation}

This research employs a $2 \times 3$ factorial design, crossing personality type (introverted, extraverted) with brainstorming method (traditional group brainstorming, hybrid method 1 and 2) to test the defined hypotheses $\mathrm{H} 1-\mathrm{H} 4$. This is complemented by a survey to test H5-H6.

The first independent variable is personality type (IV-I), which includes the two levels of introverted and extraverted personality type. The classification and belonging of participants to one of these two levels is defined by means of a personality test, namely IPIP-NEO-120, developed by Johnson (2014). The IPIPNEO-120 is a 120-item inventory that can be administered on the World Wide Web and measures the five broad domains of the Five-Factor Model (Goldberg, 1990). These domains consist of Neuroticism, Extraversion, Conscientiousness, Agreeableness and Openness to Experience (Johnson, 2014), whereof Extraversion is the scale of interest to this study. The score ranges from 0-100, 100 being extremely extraverted. Students with a score below 40 are categorized as introverts, above 60 as extraverts and between 40 and 60 as average. The scores are reported as percentile estimates. To illustrate, a score of 70 means that the level on extraversion is estimated to be higher than $70 \%$ of persons of the same sex and age (Johnson, 2014). Cronbach's alpha reliability estimates are available for all IPIP scales, whereof the scales measuring extraversion yield a mean score of .84 to .89 , depending on the sample the estimates were based upon. One determinant of the test's validity are the correlation coefficients to constructs similar to the IPIPNEO-120, whereof the correlation to the NEO-PI-R totals .85 .

The second independent variable is brainstorming method (IV-II), including the three levels of traditional group brainstorming, hybrid method 1 and hybrid method 2 . These brainstorming methods entail three different conditions. First, the condition of the traditional group brainstorming method (G), which encompasses brainstorming in a group for a time of eight minutes. Second, the condition of hybrid method 1 entails first brainstorming individually for half of the time, i.e. four minutes, and consecutively, in a group for four minutes (IG). The third method, namely hybrid method 2, entails first brainstorming individually, then in a group, then again individually and then in a group for two minutes each (IGIG).

The dependent variable of the experimental design is defined as the average quantitative, non-redundant ideas generated per participant and personality type per group (DV- I), called "average ideas generated" hereafter, for reasons of simplicity. This implies that two scores are assigned to every brainstorming group after each of the three brainstorming rounds. First, one average score of non-redundant ideas produced by introverted, and second, one average score produced by extraverted group members. Since the underlying research question asks whether hybrid brainstorming can empower introverts to contribute an assimilable amount of ideas compared to extraverts, the focus of this research solely lies on the quantity of ideas produced. The quality of ideas is neglected at this point. The dependent variable is measured by counting the numbers of ideas produced per group and personality type.

The dependent variable of the survey is post-brainstorming satisfaction (DV-II). This construct is measured by the following four items: Were you satisfied with the (1) process, (2) the results, (3) your own contribution to this brainstorming round and (4) how satisfied were you overall. These items are measured using a questionnaire with 5-point Likert Scales, ranging from very unsatisfied (1) to very satisfied (5). The average of these four items is reported per participant. The short questionnaire, which includes four questions, was adopted from Valacich, Dennis and Nunamaker (1992). Overall, the scale was reliable (Cronbach's alpha: .74). 


\section{Data Collection}

The experiment was conducted during three different days (see figure 1 for an overview of the process of experiment). As a first step, test persons were asked to complete the online personality test IPIP-NEO120 (Johnson 2014) using fictitious nicknames. Next, they were sorted into three subgroups (1) introverted (extraversion score below 40), (2) extraverted (score above 60), and (3) average (score between 40 and 60). Based on a provided list including their nicknames and their personality types, the test persons were assigned to one of the brainstorming groups, consisting of one introverted and two to three extraverted each. Thereafter, the participants received an introduction on the general procedure, including the idea generation and coding in brainstorming.

After having received the instructions, the participants conducted a small test-round to become familiar with the procedure. The first brainstorming round used the traditional group brainstorming method according to the rules of Osborn (called "G-condition"). Therefore, the participants were asked to brainstorm as a group for eight minutes. At day 1, their task was to consider possible product differentiations of a chocolate brand (the task is called "chocolate"). Since counterbalancing was used in this study, the order of tasks varied on each day (see figure 1). On day 2, the first task was to think of possible marketing actions for the promotion of a new product of smoothie brand (called "smoothie"), and on day 3, their first task was to think of products that could be sold under a newly introduced product line of a supermarket (called "supermarket"). Next, the second brainstorming round was conducted, employing hybrid method 1. This entails switching from individual phases to group phases. Therefore, the students first brainstormed individually (I) for four minutes and then in a group (G) for four minutes (called "IG-condition"). The final brainstorming round used hybrid method 2 . The process first entailed an individual phase (I), followed by a group phase $(\mathrm{G})$, an individual phase (I) and a group phase $(\mathrm{G})$ another group phase for 2 minutes each (called "IGIG-condition").

FIGURE 1

PROCESS OF EXPERIMENT

\begin{tabular}{|c|c|c|c|c|}
\hline $\begin{array}{l}\text { Brainstorming } \\
\text { Method }\end{array}$ & $\begin{array}{l}\text { Traditional } \\
\text { Group } \\
\text { Brainstorming }\end{array}$ & $\begin{array}{l}\text { Traditional } \\
\text { Group } \\
\text { Brainstorming }\end{array}$ & $\begin{array}{l}\text { Hybrid } \\
\text { Method } 1\end{array}$ & $\begin{array}{l}\text { Hybrid } \\
\text { Method } 2\end{array}$ \\
\hline $\begin{array}{l}\text { Brainstorming } \\
\text { Condition }\end{array}$ & $\begin{array}{c}\text { Test } \\
\text { Round (G) }\end{array}$ & G & IG & IGIG \\
\hline $\begin{array}{l}\text { Brainstorming } \\
\text { Time/Phase }\end{array}$ & $\begin{array}{l}3 \text { minutes } \\
\text { per phase }\end{array}$ & $\begin{array}{l}8 \text { minutes } \\
\text { per phase }\end{array}$ & $\begin{array}{l}4 \text { minutes } \\
\text { per phase }\end{array}$ & $\begin{array}{l}2 \text { minutes } \\
\text { per phase }\end{array}$ \\
\hline $\begin{array}{l}\text { Brainstorming } \\
\text { Task }\end{array}$ & $\begin{array}{l}\text { Day 1: Test Round } \\
\text { Day 2: Test Round } \\
\text { Day 3: Test Round }\end{array}$ & $\begin{array}{l}\text { Day 1: Chocolate } \\
\text { Day 2: Smoothie } \\
\text { Day 3: Supermarket }\end{array}$ & $\begin{array}{l}\text { Day 1: Smoothie } \\
\text { Day 2: Supermarket } \\
\text { Day 3: Chocolate }\end{array}$ & $\begin{array}{l}\text { Day 1: Supermarket } \\
\text { Day 2: Chocolate } \\
\text { Day 3: Smoothie }\end{array}$ \\
\hline $\begin{array}{l}\text { Individual (I) and } \\
\text { Group (G) Phases }\end{array}$ & Group & Individual / Group & IGIG Individual & oup / Individual / Group \\
\hline
\end{tabular}

The collected data hence consisted of two components. First, the sticky notes that are used to measure the DV-I, namely the average ideas generated and second, questionnaires that are used to measure the DVII, namely post-brainstorming satisfaction.

\section{Data Analysis Methods}

The primary hypotheses were tested using a two-way mixed design ANOVA, followed by several posthoc tests. The statistical test of a two-way mixed design ANOVA compares the differences in means 
between groups that are split on two independent variables, as in the case of this research. These variables comprise one between-subjects factor that has two independent groups, i.e. introverted or extraverted, and one within-subjects factor that has three related groups and is repeatedly measured, i.e. three different brainstorming methods in this case. Since the statistical test perfectly reflects the design of this research, it was well-suited to choose for analysis. The primary purpose of using the two-way mixed design ANOVA is to understand if there is an interaction between the between-subjects and within-subjects factor in relation to the dependent variable (Laerd Statistics, 2015a). To conduct the test, two average scores of nonredundant ideas, i.e. one average score for introverts and one for extraverts, were derived per group. Since the two-way mixed design ANOVA only reveals whether an interaction exists between the betweensubjects factor and within-subjects factor on a dependent variable, the two-way mixed design ANOVA was consequently followed-up by independent-samples t-tests and paired-samples t-tests to test hypotheses H1H4.

To understand if an interaction between personality type and brainstorming method that affects postbrainstorming satisfaction exists, the two-way mixed design ANOVA was applied again. This involved the between-subjects factor of personality type, i.e. introverted or extraverted, and the within-subjects factor of brainstorming methods, including the three brainstorming methods applied. The hypotheses H5-H6 were further tested using paired-samples t-tests. This test is utilized to determine if there is a statistically significant difference between paired observations (Laerd Statistics, 2015b).

\section{Validity and Reliability}

According to Sani and Todman (2008), three important aspects of validity apply to experiments, namely internal, external and construct validity. Internal validity refers to "the extent to which causal conclusions can be drawn" (Gray, 2004). Since we cannot generally exclude the existence of other variables that influence our dependent variable, nuisance variables (NVs) need to be discussed and eliminated as far as possible (Sani \& Todman, 2008). These variables are "undesired sources of variation in an experiment that affect the dependent variable" (Kirk, 2013). There are two ways of control, namely to eliminate the NV by keeping it constant throughout the experiment, or by turning it into a random variable (Sani \& Todman, 2008). Even though there are no perfectly designed experiments, great diligence has been taken in creating a sound experimental design. Therefore, the random allocation of subjects to the groups has been assured, which is one controlling element for threats to validity (Gray, 2004).

External validity refers to "the extent to which it is possible to generalize from the data to a larger population or setting" (Gray, 2004). However, reducing the threat to internal validity and designing an experiment as representatively and realistically as possible, is contradictive (Sani \& Todman, 2008). Therefore, external validity can only be improved to the degree that it does not hamper internal validity. First, regarding ecological validity, i.e. generalizing the findings to different settings (Sani \& Todman, 2008), it can be stated that the experimental setting of a classroom for brainstorming sessions is somehow comparable to real-world settings. To illustrate, a meeting room at a company equals a classroom to a large extent. However, the presence of various brainstorming groups at a time is rather seldom. Second, referring to population validity, i.e. generalizing the findings to people differing from the sample (Sani \& Todman, 2008), it needs to be noted that the results of students cannot fully be generalized to other populations.

"Construct validity is the extent to which a variable actually reflects the theoretical construct that we intend to measure" (Sani \& Todman, 2008). The underlying condition is to operationally define all involved concepts before measuring them (Gray, 2004). In case of this research, the concepts of the IVs as well as the DVs were scrutinized and operationalized in chapter 2, leading to present construct validity.

Experimental reliability refers to "consistency, stability, or repeatability of the results of an experimental study" (Christensen, 2008). To conduct a reliable experiment, all components involved, i.e. number and identification of participants, as well as the dependent and independent variables, must be reliable. Regarding the number and identification of participants, a sufficient number of participants increases the reliability of the obtained results (Christensen, 2008). In case of this research, a total of $\mathrm{N}=$ 87 , whereof $\mathrm{N}=62$ were subject for analysis, was regarded as sufficient to obtain reliable statistical results, since all statistical tests selected could be carried out while meeting the required assumptions. The 
subsequent partition into three sub groups based on personality type, relied on a reliable personality test (Cronbach's alpha .08 to 89 for extra-version scale), namely IPIP-NEO-120 (Johnson, J. A., 2014).

\section{RESULTS OF THE NEW STUDY}

In the first instance, a two-way mixed design ANOVA was carried out to explore if there exists an interaction between the between-subjects and within-subjects factor in relation to the dependent variable, namely average ideas generated (DV-I). In the present case, personality type (IV-I) was the two-level between-subjects factor and brainstorming method (IV-II) the three-level within-subjects factor.

TABLE 2

MEANS AND STANDARD DEVIATIONS OF AVERAGE IDEAS GENERATED FOR TRADITIONAL BRAINSTORMING, HYBRID METHOD $1 \& 2$

\begin{tabular}{|llll|}
\hline & $\begin{array}{l}\text { Traditional } \\
\text { [G-condition] }\end{array}$ & $\begin{array}{l}\text { Hybrid method 1 } \\
\text { [IG-condition] }\end{array}$ & $\begin{array}{l}\text { Hybrid method 2 } \\
\text { [IGIG-condition] }\end{array}$ \\
\hline Introverts & & & \\
$\boldsymbol{M}$ & 3.81 & 4.13 & 5.94 \\
SD & 1.94 & 2.63 & 3.43 \\
\hline Extraverts & & & \\
$\boldsymbol{M}$ & 6.77 & 6.87 & 8.29 \\
SD & 1.97 & 2.72 & 2.43 \\
\hline
\end{tabular}

Table 2 presents the means and standard deviations of average ideas generated (DV-I), sorted by personality type (IV-I) and brainstorming method (IV-II), respectively. In the following, figure 2 further graphically illustrates the derived results of the mean average ideas generated, sorted for personality type and brainstorming method.

FIGURE 2

MEAN AVERAGE IDEAS GENERATED IN TRADITIONAL BRAINSTORMING, HYBRID METHOD $1 \& 2$ ACCORDING TO PERSONALITY TYPE

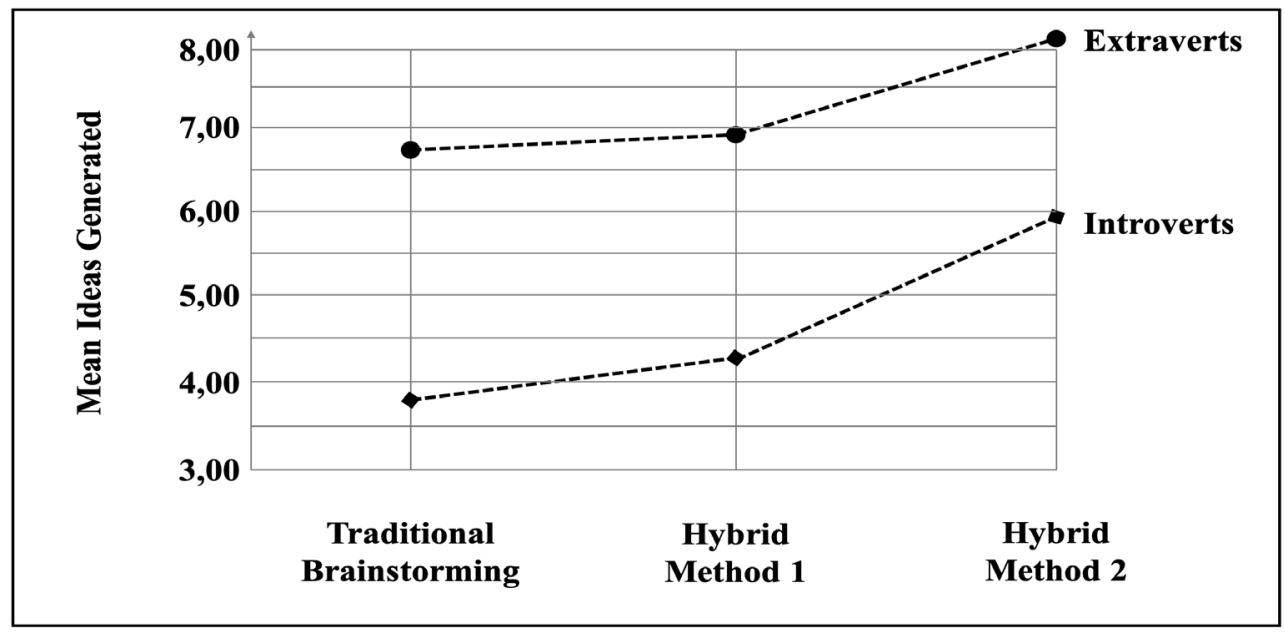

Investigating the assumptions of the two-way mixed design ANOVA revealed that there were no outliers in the present data set, as assessed by inspection of a boxplot and by examination of studentized 
residuals for values greater than \pm 3 . In addition, DV-I was normally distributed, as assessed by ShapiroWilk's test ( $\mathrm{p}>.05)$ and by Normal Q-Q Plot. Besides, there was homogeneity of variances, as assessed by Levene's test of homogeneity of variance $(p>.05)$ and homogeneity of covariances, as assessed by Box's test of equality of covariance matrices $(\mathrm{p}=.063)$. Mauchly's test of sphericity indicated that the assumption of sphericity was met for the two-way interaction $\chi 2(2)=.993, p=.609$. Running the test revealed that there was no statistically significant interaction between personality type (IV-I) and brainstorming method (IV-II) on average ideas generated (DV- I), $\mathrm{F}(2,60)=.201, \mathrm{p}=.818$, partial $\eta 2=.007$. Therefore, it was further tested for main effects. The main effect of brainstorming method revealed a statistically significant difference in average ideas generated within the three different brainstorming methods, $\mathrm{F}(2,60)=8,537, \mathrm{p}$ $=.001(\mathrm{p}<.05)$, partial $\eta 2=.222$. This demonstrates that the average ideas generated significantly differed for the three brainstorming methods applied during the experiment. A pairwise comparison further disclosed that the mean difference is significant at the .05-level for (1) the traditional meth-od (G-condition) compared to hybrid method 2 (IGIG-condition), as well as for (2) the hybrid method 1 (IG-condition) compared to hybrid method 2 (IGIG-condition). Likewise, the main effect of personality type showed that there was a statistically significant difference in average ideas generated between the two types $F(1,30)=$ $14,023, \mathrm{p}=.001$, partial $\eta 2=.319$. This depicts an existence of significant differences between brainstorming performance according to personality type. The lack of statistically significant simple main effects, as laid out above, however, indicates that the differences in average ideas generated between the two personality types (IV-I) and three brainstorming methods (IV-II) cannot be traced back to the existence of an interplay between these two variables that jointly affect the DV-I. Still, the presence of main effects for both brainstorming method and personality type ascribes a general - though separate - effect of these two variables on average ideas generated (DV-I). Further post-hoc tests, namely independent-samples ttests and paired-samples t-tests, were carried out to test hypothesis $\mathrm{H} 1-\mathrm{H} 4$.

\section{Hypothesis 1}

An independent samples t-test was run to determine whether there exists a significant difference in average ideas generated between introverts and extraverts when applying the traditional brainstorming method. Descriptive statistics indicated that extraverts $(6.77 \pm 1.97)$ generated more ideas on average compared to introverts $(3.81 \pm 1.94)$. Checking the independent samples t-test's underlying assumption revealed that there were no outliers in the data, as assessed by inspection of a boxplot. Average number of ideas generated for each level of personality, i.e. introvert and extravert, were normally distributed, as assessed by Shapiro-Wilk's test $(\mathrm{p}>.05)$. Besides, there was homogeneity of variances, as assessed by Levene's test for equality of variances $(\mathrm{p}=.768)$. Running the test indicated that there was a statistically significant difference in the mean average of ideas generated between extraverts and introverts, with introverts scoring lower than extraverts to a degree of -2.96 ideas $(95 \% \mathrm{CI},-4.37$ to -.55$), \mathrm{t}(30)=4.277$, $\mathrm{p}<.0005$. Conclusively, $\mathrm{H} 1$ is accepted.

\section{Hypothesis 2}

To determine whether introverts generate significantly more ideas when applying a hybrid method compared to the traditional method, two separate t-tests were conducted. First, comparing the traditional to the hybrid method 1, introverts generated more ideas on average while applying the hybrid method (4.13 \pm $2.63)$ as opposed to the traditional brainstorming method $(3.81 \pm 1.94)$. A paired-samples t-test was used to determine whether there was a statistically significant mean difference in average ideas generated between the two methods. There were no outliers in the data, as assessed by inspection of a boxplot. The differences between the averages of ideas generated by introverts in the traditional and hybrid method 1 were normally distributed, as assessed by Shapiro-Wilk's test $(\mathrm{p}=.554)$. However, the observed increase is not statistically significant $(\mathrm{p}>.05)$.

Second, comparing the traditional to the hybrid method 2, introverts generated more ideas when applying the hybrid method $2(5.94 \pm 3.43)$ as opposed to the traditional brainstorming method $(3.81 \pm$ 1.94). There were no outliers in the data, as assessed by inspection of a boxplot. The differences between the traditional brainstorming method and hybrid method 2 were normally distributed, as assessed by 
Shapiro-Wilk's test $(\mathrm{p}=.501)$. The hybrid method 2 elicited an increase of 2.13 ideas generated $(95 \% \mathrm{CI}$, 0.20 to 4.05 ) on average compared to the traditional method. This increase is statistically significant, $t(15)$ $=2.353, \mathrm{p}=0.033(\mathrm{p}<0.05)$.

Accordingly, $\mathrm{H} 2$ is rejected for the case of hybrid method 1, but accepted for the case of hybrid method 2 , which caused a significant increase in average ideas generated by introverts compared to the traditional brainstorming method.

\section{Hypothesis 3}

To test whether introverts and extraverts contribute equal shares to the total amount of ideas generated when applying hybrid methods, it was first analysed whether there still exists a significant difference between the types when applying hybrid method 1. Descriptive statistics indicated that introverts still contribute less ideas on average $(4.13 \pm 2.63)$ compared to extraverts $(6.87 \pm 2.72)$. The score of average ideas generated by introverts was 2.75 ideas $(95 \%$ CI, -4.68 to -0.02$)$ lower than of extraverts. An independent-samples t-test was run to determine if this difference is significant. There were no outliers in the data, as assessed by inspection of a boxplot. Average number of ideas generated was normally distributed, as assessed by Shapiro-Wilk's test $(\mathrm{p}>.05)$. Besides, there was homogeneity of variances, as assessed by Levene's test for equality of variances $(p=.627)$. The difference in mean score of average ideas generated between introverts and extraverts was proven to be significant, $t(30)=-2.908, p=.007$. This demonstrates that the gap of average ideas generated between the two personality types could not be overcome by hybrid method 1 .

Second, it was scrutinized whether the same is true for hybrid method 2. Therefore, another independent-samples t-test was run. Descriptive statistics indicated that the mean score of average ideas generated by extraverts $(8.293 \pm 2.43)$ was higher than of introverts $(5.938 \pm 3.435)$. Hence, introverts' score was $2.36(95 \% \mathrm{CI},-4.503$ to -0.207$)$ lower than of extraverts There were no outliers in the data, as assessed by inspection of a boxplot. Average ideas generated was normally distributed, as assessed by Shapiro-Wilk's test $(p>.05)$ and there was homogeneity of variances, as assessed by Levene's test for equality of variances $(\mathrm{p}=.118)$. Again, a statistically significant difference in the mean score of average ideas generated between introverts and extraverts was proven for hybrid method $2, t(30)=-2.239, \mathrm{p}=.033$. This result implies, that the method could overcome the gap of average ideas generated between introverts and extraverts either. Conclusively, $\mathrm{H} 3$ is rejected.

\section{Hypothesis 4}

To find whether introverts contribute significantly more ideas in hybrid method 2 compared to hybrid method 1, since more frequent changes are involved, a paired-samples t-test was conducted. Descriptive statistics already indicated that introverts generated more ideas applying the hybrid method 2 (5.94 \pm 3.43$)$ as opposed to hybrid meth-od $1(4.13 \pm 2.63)$. The assessment of test assumptions depicted no outliers in the data, as checked by inspection of a boxplot. Further, the differences between the average ideas generated by introverts in hybrid method 1 compared to hybrid method 2, were normally distributed, as assessed by Shapiro-Wilk's test $(\mathrm{p}=.612)$. Result of the t-test indicated that the hybrid method 2 elicited a statistically significant increase in average ideas generated to hybrid method $1, t(15)=3.131, p=0.007$. Therefore, $\mathrm{H} 4$ is accepted.

\section{Hypothesis 5 \& 6}

To test the second part of the derived hypotheses, the results from the post-brainstorming satisfaction survey were analyzed. A total of $\mathrm{N}=62$, including 16 introverts and 46 extraverts, was considered for data analysis. First, the two-way mixed ANOVA was run to test whether there exists an interaction between personality type (IV-I) and brainstorming method (IV-II) that affects post-brainstorming satisfaction (DVII). Results of descriptive statistics can be found in table 3 . 
TABLE 3

MEANS AND STANDARD DEVIATIONS OF POST-BRAINSTORMING SATISFACTION AFTER TRADITIONAL GROUP BRAINSTORMING AND HYBRID METHOD $1 \& 2$

\begin{tabular}{|lccc|}
\hline & $\begin{array}{c}\text { Traditional } \\
\text { [G-condition] }\end{array}$ & $\begin{array}{c}\text { Hybrid method 1 } \\
\text { [IG-condition] }\end{array}$ & $\begin{array}{c}\text { Hybrid method 2 } \\
\text { [IGIG-condition] }\end{array}$ \\
\hline Introverts & & & \\
M & 3.86 & 3.86 & 3.94 \\
SD & 0.55 & 0.87 & 0.72 \\
\hline Extraverts & & & \\
M & 4.12 & 4.10 & 4.25 \\
SD & 0.56 & 0.66 & 0.79 \\
\hline
\end{tabular}

Figure 3 further illustrates the derived results by showing mean post-brainstorming satisfaction sorted for personality type and brainstorming method.

FIGURE 3

MEAN POST-BRAINSTORMING SATISFACTION AFTER TRADITIONAL GROUP BRAINSTORMING AND HYBRID METHOD $1 \& 2$

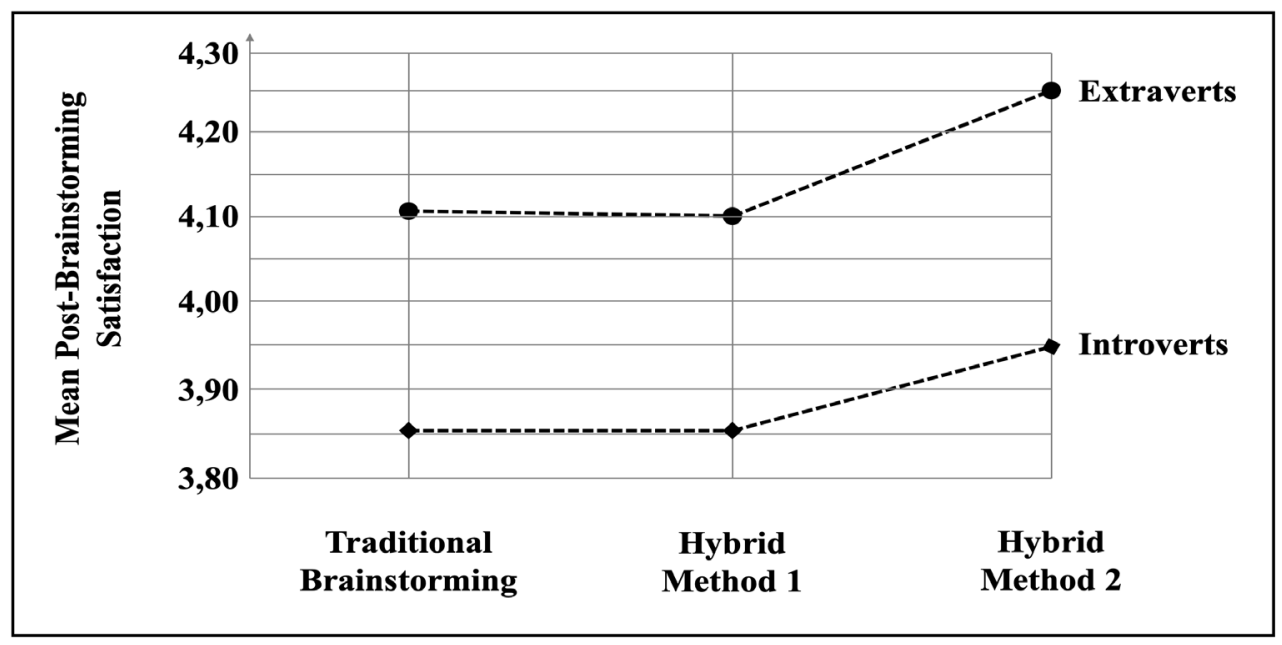

An independent samples t-test was run to test H5, questioning whether introverts show a lower satisfaction level after traditional brainstorming compared to extraverts. Again, one outlier was detected that was more than 1.5 box-lengths from the edge of the box in a boxplot. Inspection of its value did not reveal it to be extreme and hence it was kept in the analysis. The score for average generated ideas was normally distributed in case of the needed data set, as assessed by Shapiro-Wilk's test ( $\mathrm{p}>.05)$. Besides, there was homogeneity of variances, as assessed by Levene's test for equality of variances $(\mathrm{p}=.471)$. Descriptive statistics indicate that mean extravert satisfaction score $(4.12 \pm 0.56)$, after applying the traditional method, was higher than mean introvert satisfaction score $(3.86 \pm 0.55)$. However, this difference was not statistically significant, $\mathrm{t}(59)=-1.592, \mathrm{p}=.117$.

To test H6, a paired-samples t-test was used to determine whether there was a statistically significant difference between the post-brainstorming satisfaction level of introverts after hybrid brainstorming compared to traditional brainstorming. First, satisfaction levels after the traditional and hybrid method 1 were compared. There were no outliers in the data, as assessed by boxplot. The differences between the satisfaction scores of introverts applying the traditional brainstorming method and hybrid method 1 were normally distributed, as assessed by Shapiro-Wilk's test $(\mathrm{p}=.221)$. Descriptive statistics already revealed 
that introverted participants indicated an exact same satisfaction level after the traditional brainstorming round $(3.86 \pm 0.55)$ as opposed to the first hybrid brainstorming round $(3.86 \pm 0.87)$. Consequently, the hybrid method 1 did not elicit any increase in satisfaction level (95\% CI, -0.386 to 0.386). There was no significant difference between the satisfaction levels $(\mathrm{p}=1.000)$.

Second, the post-brainstorming satisfaction levels of introverts after the traditional and the hybrid method 2 were compared. The difference scores for the traditional method and hybrid method 2 were normally distributed, as assessed by Shapiro-Wilk's test $(\mathrm{p}=.621)$. According to descriptive statistics, introverted participants were more satisfied after hybrid method $2(4.02 \pm 0.67)$ as opposed to the traditional method (3.82 \pm 0.54$)$. Hence, the hybrid brainstorming method, elicited an increase of 0.200 (95\% CI, 0.132 to 0.532 ) in post-brainstorming satisfaction compared to the traditional method. However, this increase was not significant, $\mathrm{t}(14)=1.293, \mathrm{p}=.217$. Conclusively, both $\mathrm{H} 5$ and H6 are rejected. Finally, an overview of the results for all hypotheses can be found in table 4 .

\section{TABLE 4 \\ OVERVIEW OF HYPOTHESES TEST RESULTS}

\begin{tabular}{|c|c|c|}
\hline & Hypotheses & Test results \\
\hline $\mathrm{H} 1$ & $\begin{array}{l}\text { In traditional interactive group brainstorming, } \\
\text { introverted group members contribute significantly less } \\
\text { to the total amount of ideas generated, compared to } \\
\text { extraverted group members }\end{array}$ & Accepted $(\mathrm{p}<.0005)$ \\
\hline $\mathrm{H} 2$ & $\begin{array}{l}\text { In hybrid brainstorming, introverted group members } \\
\text { contribute significantly more to the total amount of } \\
\text { ideas generated, compared to traditional interactive } \\
\text { group brainstorming }\end{array}$ & $\begin{array}{l}\text { Rejected for hybrid method } 1 \\
(\mathrm{p}>.05) \\
\text { Accepted for hybrid method } 2 \\
(\mathrm{p}<.05)\end{array}$ \\
\hline H3 & $\begin{array}{l}\text { In hybrid brainstorming, introverted and extraverted } \\
\text { group members contribute equal shares to the total } \\
\text { amount of ideas generated }\end{array}$ & $\begin{array}{l}\text { Rejected for hybrid method } 1 \\
(\mathrm{p}=.007)^{1} \\
\text { Rejected for hybrid method } 2 \\
(\mathrm{p}=.033)^{1}\end{array}$ \\
\hline $\mathrm{H} 4$ & $\begin{array}{l}\text { In hybrid brainstorming, introverted group members } \\
\text { contribute significantly more ideas if frequent changes } \\
\text { between individual and group phases are included, } \\
\text { compared to less frequent changes }\end{array}$ & Accepted $(p=0.007)$ \\
\hline H5 & $\begin{array}{l}\text { Introverted group members show a lower satisfaction- } \\
\text { level after traditional interactive group brainstorming } \\
\text { compared to extraverted group members }\end{array}$ & Rejected $(\mathrm{p}=.117)$ \\
\hline \multirow[t]{2}{*}{ H6 } & $\begin{array}{l}\text { Introverted group members show a higher satisfaction- } \\
\text { level after hybrid brainstorming compared to } \\
\text { traditional brainstorming }\end{array}$ & $\begin{array}{l}\text { Rejected for hybrid method } 1 \\
(\mathrm{p}=1.000) \\
\text { Rejected for hybrid method } 2 \\
(\mathrm{p}=.217)\end{array}$ \\
\hline & ${ }^{1} \mathrm{H} 1: \mu_{\text {introverts }} \neq \mu_{\text {extraverts }}$ & \\
\hline
\end{tabular}

\section{DISCUSSION}

First, the results attested a general existence of differences in average ideas generated between introverts and extraverts. However, this cannot be traced back to an interplay between applied brainstorming method and personality type. Still, results indicate that both personality type and brainstorming method have an effect on the outcome of brainstorming. This fortifies earlier findings which have already accredited personality with an impact on brainstorming performance (Callaghan, 2009; Camacho \& Paulus, 1995). Previous research has also provided evidence that particularly differences in the 
introversion-extraversion dimension can play a significant role in brainstorming (Bradley \& Hebert, 1997; Jung et al., 2012), which was likewise confirmed with this research. The findings of the present study hence support the "New Groupthink's" claim that personality differences can be made accountable for variances in brainstorming productivity (Cain, 2013; Dossey, 2016). Besides, results also accredit a general difference in brainstorming performance of introverts between traditional and hybrid methods.

For hypothesis $1(\mathrm{H} 1)$, it was predicted that in traditional interactive group brainstorming, introverted group members contribute significantly less to the total amount of ideas generated, compared to extraverted group members. This assumption was proved and therewith replicates previous research. Although only a few studies have broached this issue earlier, already Callaghan (2009) showed introverts to be less involved in brainstorming sessions. The present result again underlines the argument of the "New Groupthink" theory (Cain, 2013).

Regarding hypothesis $2(\mathrm{H} 2)$, the expectation was that in hybrid brainstorming introverted group members would contribute significantly more to the total amount of ideas generated, compared to traditional group brainstorming. This hypothesis was shown to be significant for hybrid method 2, however not for hybrid method 1. Still, introverts generated more ideas on average in both, hybrid method $1(4.13 \pm 2.63)$ and hybrid method $2(5.94 \pm 3.43)$, compared to the traditional method (3.81 \pm 1.94$)$. A general increase in ideas when applying hybrid brainstorming was attested earlier in literature, however regardless of personality type (Girotra et al., 2010; Jung et al., 2012; Korde, 2014; Korde \& Paulus, 2017). In the present research, based on the average ideas generated in the traditional method, introverts showed a relatively larger increase in mean ideas when applying hybrid method $1(+8.40 \%)$ and hybrid method $2(+55.91 \%)$ compared to extraverts $(+1.48 \%$ in hybrid method 1 and $+22.45 \%$ in hybrid method 2$)$. The divergence in findings concerning the two hybrid methods can be traced back to more frequent changes between individual and group phases that are involved in hybrid method 2. Conclusively, hybrid brainstorming methods have the power to enhance the contribution of introverts, whose performance can be maximized when frequent and fast changed between quiet and group phases are involved.

Hypothesis $3(\mathrm{H} 3)$ forecasted that in hybrid brainstorming, introverted and extraverted group members contribute equal shares to the total amount of ideas generated. This prediction was statistically insignificant for both hybrid method 1 and hybrid method 2. Introverts still contributed significantly less ideas on average compared to extraverts, who generated the most ideas in each condition. The insignificant results mainly occur because not only introverts but both personality types experienced an increase in average ideas generated within the hybrid methods. Consequently, the performance gap could be reduced but not be closed. However, the difference in mean ideas generated between the two personality types narrowed when applying the hybrid methods. Even though introverts benefit slightly more from hybrid brainstorming compared to extraverts, and increase their overall amount of ideas, the method cannot overcome the performance gap between the two personality types.

For hypothesis $4(\mathrm{H} 4)$, it was predicted that in hybrid brainstorming, introverted group members contribute significantly more ideas if frequent changes between individual and group phases are included. This hypothesis was accepted. Hence, introverts contributed significantly more ideas in hybrid condition 2 compared to hybrid condition 1 . Neither has any study particularly investigated the effect of the number of changes between group and individual conditions, nor its impact on the performance of introverts. Therefore, this result adds original contributions to the respective body of research and cannot be directly compared to earlier findings. However, it is in line with inferences derived from prior studies in the field of brainstorming and personality (Korde \& Paulus, 2017; Paulus, Korde, Dickson, Carmeli \& Cohen-Meitar 2015; Paulus \& Yang, 2000). This likewise supports Cain (2013), who argues that introverts reenergize through solitude, which in turn functions as a catalyst to innovation.

With regards to post-brainstorming satisfaction of introverts, results indicated that post-brainstorming satisfaction cannot be directly traced back to personality type or brainstorming method. Since no other study has yet compared satisfaction levels of introverts and extraverts after hybrid brainstorming, this result cannot be compared directly to earlier publications.

Regarding hypothesis 5 (H5), it was expected that introverted group members show a lower satisfaction-level after traditional interactive group brainstorming compared to extraverted group members. 
This prediction had to be rejected. The satisfaction level of introverts was lower, however not significantly lower after traditional group brainstorming. This result is to some extent surprising when reviewing earlier literature. In this regard, it was found that introverts oftentimes perceive meetings and group discussions, such as brainstorming, to be an energy drain (Culp \& Smith, 2005). In case of the present research, irrespective of their inferior performance, introverts seem to enjoy traditional group brainstorming (satisfaction level: 3.86), although a little less than extraverts (satisfaction level: 4.12).

The hypothesis 6 (H6), which assumed that introverted group members show a higher satisfaction-level after hybrid brainstorming compared to traditional brainstorming, was likewise rejected. Since hybrid brainstorming comes along with individual reflection phases and hence time to think things through before discussing as a group, it was assumed that introverts prefer hybrid brainstorming over the traditional method (Callaghan, 2009). However, in contrast to expectations, no differences in introverts' satisfaction levels could be noted between the traditional and hybrid method 1. One reason for this discrepancy could be that introverts already reported quite high satisfaction levels after the traditional method and did not leave much room for higher scores. Regarding the difference of introverts' post-brainstorming satisfaction between the traditional and hybrid method 2, a slight - though not significant - increase could be observed. This increase can be traced back to the advantages that come along with the involvement of multiple changes between the two conditions, as discussed before. Conclusively, it can be stated that introverts feel more satisfied when applying hybrid brainstorming methods, while involving multiple changes between quiet and group phases satisfies them the most.

Finally, referring back to the research question, asking whether hybrid brainstorming can empower introverts to contribute an assimilable amount of ideas compared to extraverts, the following conclusion must be drawn: The method of hybrid brainstorming alone does not have enough power to close the gap between introverts and extraverts. In fact, extraverts still generate the most ideas in all brainstorming conditions. However, hybrid brainstorming helps to enhance both the contribution of introverts and their post-brainstorming satisfaction.

\section{CONCLUSIONS, LIMITATIONS AND IMPLICATIONS}

\section{Conclusions}

This research illustrated the "New Groupthink" theory's standpoint with regards to the widely-used collaborative ideation method of group brainstorming, still being the most commonly adopted approach for generating creative ideas (Korde \& Paulus, 2017; Rietzschel et al., 2006). Since the method's application in its traditional form was found to be to the detriment of introverts (Callaghan, 2009; Camacho \& Paulus, 1995), one alternative method, namely hybrid brainstorming - which alters between individual and group brainstorming - was investigated within this research. Due to the fact that no research has yet investigated whether hybrid brainstorming helps to overcome the discrepancy between the contribution of introverts and extraverts in group brainstorming, this research has stepped into that gap. Consequently, the main aim of this study was to explore whether hybrid brainstorming empowers introverts to contribute an assimilable amount of ideas compared to extraverts.

Consequently, besides the overall conclusion, this research raises some relevant considerations regarding brainstorming. First, it can be stated that introverts tend to underperform in collaborative forms of ideation, which again underlines the existence of natural differences between introverts and extraverts that should not be disregarded. More specifically, this finding demonstrates that personality, although widely neglected in brainstorming literature, plays an important role in the search for the best brainstorming performance and that the empowerment of introverts constitutes a determining factor for success.

Furthermore, hybrid brainstorming was found to generally surpass traditional group brainstorming with regards to the quantity of ideas generated and post-brainstorming satisfaction levels. Hence, in contrast to traditional group brainstorming, this method possesses the ability of enhancing the overall brainstorming performance of introverts. Besides, although to a smaller extent, extraverts also displayed higher satisfaction and performance levels when using hybrid brainstorming. This further demonstrates the method's general superiority over traditional group brainstorming. In particular, introverts were found to 
be most satisfied and to perform best when frequent changes between individual and group brainstorming were involved. As a consequence, a need to rethink and adapt existing ideation methods to accommodate all personality types and finally obtain the best results arises.

Concerning satisfaction in brainstorming, it can be concluded that, irrespective of their lesser performance, introverts do not feel dissatisfied or unhappy after brainstorming. In fact, they seem to enjoy both the traditional and hybrid method, whereof the latter is slightly favoured. This speaks for the existence of the positive effects this method can have on participants, which go beyond the pure quantity of ideas generated. Therefore, applying interactive group-, or hybrid brainstorming can satisfy participants. They generally feel contributory - a factor that should not be neglected in the "New Groupthink" discussion.

The derived conclusions add original contributions to the respective body of research. First, they contribute new insights to the scarcely covered academic area concerning the personality's impact on brainstorming performance and underline its decisive role. Second, no previous research had found adequate solutions of overcoming the productivity barrier between introverts and extraverts in group brainstorming. What is more, it was the first of its kind to explore whether hybrid brainstorming has the power to close the performance gap between the two personality types. Third, unlike any other study, this research also compared satisfaction levels of introverts and extraverts in traditional group and hybrid brainstorming in addition to the widely-used measure of average ideas generated.

\section{Limitations}

A number of limitations must be acknowledged with regards to the generalizability of this study. First, regarding the study's sample, it needs to be noticed that a non-random sampling method, namely convenience sampling, was applied for practical reasons. Although the sample size was regarded to be sufficient, including a larger sample would have facilitated a greater statistical power. Furthermore, an equal spread between introverted and extraverted participants per group would have been preferable, since an uneven distribution might have disadvantaged the contribution of the group's minority. Again, a larger sample size would have been needed to counteract this shortcoming. Besides, this study employed an experiment involving students, which is not equal to a natural group setting. Although this may be methodologically consistent with much of the research on brainstorming, this approach presents some difficulty in generalizing the obtained results to real organizational settings.

Furthermore, it should be noted that the categorization of participants according to personality type was based on trust. This shortcoming is attributable to the fact that participants needed to independently report their test scores without being controlled. These scores consequently served as basis for their categorization. Since no other comparable and feasible test procedure was available to the researcher, this limitation was not restrictable.

To conclude, exclusively three brainstorming conditions were selected for investigation, whereas others were knowingly excluded due to the limited scope of this study. Accordingly, this study is limited to the specific conditions under investigation, namely one traditional and two hybrid conditions. Furthermore, the results exclusively refer to the employed time frame of eight minutes per brainstorming round. Hence, the obtained results cannot be generalized for the traditional group- or hybrid brainstorming method as such.

Lastly, referring to delimitations, this research exclusively employed quantitative measures without any qualitative elements. This is due to this study's particular focus on empowering introverts in brainstorming by increasing their numerical share to idea contribution.

\section{Implications and Further Research}

In general, the findings derived underline the importance in organizations to recognize differences between introverted and extraverted employees. For managers, this encompasses answering to employees' diverse and individual needs regarding personality, and to facilitate corresponding working conditions. In particular, organizational areas dealing with creativity and innovation should not regard collaborative ideation as the only true form, as it is however often the case. Accordingly, for teams who frequently apply traditional group brainstorming, a switch to hybrid methods is suggested, since findings have shown that this can lead to both an increase in overall results and the contribution of introverts. Besides, it is 
recommended that managers and team leaders make use of multiple ideation methods in order to accommodate and include the ideas of various personality types.

Finally, the paper provides a first step in approaching the underperformance and suppression of introverts in collaborative ideation methods. In particular, this research concentrated on the most widely applied ideation method of group brainstorming. Since there barely exist literature concerning the impact of personality differences on brainstorming, this academic area offers a large range of possibilities for further research. In addition, it is recommended to delve into a qualitative dimension, such as researching participants' reasons behind preferring one hybrid method over another.

\section{REFERENCES}

Aguilar-Alonso, A. (1996). Personality and creativity. Personality and Individual Differences, 21(6), 959-969.

Anderson, N., Potočnik, K., \& Zhou, J. (2014). Innovation and Creativity in Organizations. Journal of Management, 40(5), 1297-1333.

Batey, M., Chamorro-Premuzic, T., \& Furnham, A. (2010). Individual Differences in Ideational Behavior: Can the Big Five and Psychometric Intelligence Predict Creativity Scores? Creativity Research Journal, 22(1), 90-97.

Bolin, A.U., \& Neuman, G.A. (2006). Personality, Process, and Performance in Interactive Brainstorming Groups. Journal of Business and Psychology, 20(4), 565-585.

Bradley, J.H., \& Hebert, F.J. (1997). The effect of personality type on team performance. Journal of Management Development, 16(5), 337-353.

Bradshaw, S.D., Stasson, M.F., \& Alexander, D. (1999). Shyness and Group Brainstorming: Effects on Productivity and Perceptions of Performance. North American Journal of Psychology, 1(2), 267275.

Briggs Myers, I. (1995). Gifts Differing: Understanding Personality Type. California: Davies-Black Publishing.

Brown, S.R., \& Melamed, L.E. (1990). Experimental design and analysis. Quantitative applications in the social sciences (Vol. 74). Newbury Park, California: Sage Publications.

Cain, S. (2012, January 13). The Rise of the New Groupthink. New York Times. Retrieved from http://www.nytimes.com/2012/01/15/opinion/sunday/the-rise-of-the-new-groupthink.html

Cain, S. (2013). Quiet: The power of introverts in a world that can't stop talking. London: Penguin.

Callaghan, E. (2009). Personalities of Design Thinking. Design Management Journal, 4(1), 20-32.

Camacho, L.M., \& Paulus, P.B. (1995). The Role of Social Anxiousness in Group Brainstorming. Journal of Personality and Social Psychology, 68(6), 1071-1080.

Christensen, L.B. (2008). Experimental methodology (10th ed.). Boston, Munich: Pearson/Allyn and Bacon.

Creswell, J.W. (2008). Research design: Qualitative, quantitative, and mixed methods approaches (2nd ed.). Thousand Oaks, California: Sage Publications.

Culp, G., \& Smith, A. (2005). Leadership Effectiveness and Behavior. Leadership and Management in Engineering, 5(2), 39-48.

DeRosa, D.M., Smith, C.L., \& Hantula, D.A. (2007). The medium matters: Mining the long-promised merit of group interaction in creative idea generation tasks in a meta-analysis of the electronic group brainstorming literature. Computers in Human Behavior, 23(3), 1549-1581.

Diehl, M., \& Stroebe, W. (1987). Productivity loss in brainstorming groups: Toward the solution of a riddle. Journal of Personality and Social Psychology, 53(3), 497-509.

Diehl, M., \& Stroebe, W. (1991). Productivity loss in idea-generating groups: Tracking down the blocking effect. Journal of Personality and Social Psychology, 61(3), 392-403.

Dossey, L. (2016). Introverts: A Defense. Explore, 12(3), 151-160.

Dubina, I.N., Carayannis, E.G., \& Campbell, D.F.J. (2012). Creativity Economy and a Crisis of the Economy? Coevolution of Knowledge, Innovation, and Creativity, and of the Knowledge Economy and Knowledge Society. Journal of the Knowledge Economy, 3(1), 1-24. 
Dunnette, M.D., Campbell, J., \& Jaastad, K. (1963). The effect of group participation on brainstorming effectiveness for 2 industrial samples. Journal of Applied Psychology, 47(1), 30-37.

Eysenck, H.J. (1995). Genius: The natural history of creativity. In J. Gray (Ed.), Problems in the behavioral sciences (p.12). Monograph. Cambridge, UK: Cambridge University Press.

Feist, G.J. (1998). A meta-analysis of personality in scientific and artistic creativity. Personality and Social Psychology Review, 2(4), 290-309.

Furnham, A. (2000). The Brainstorming Myth. Business Strategy Review, 11(4), 21-28.

Furnham, A., \& Yazdanpanahi, T. (1995). Personality differences and group versus individual brainstorming. Personality and Individual Differences, 19(1), 73-80.

Girotra, K., Terwiesch, C., \& Ulrich, K.T. (2010). Idea Generation and the Quality of the Best Idea. Management Science, 56(4), 591-605.

Goldberg, L.R. (1990). An alternative "description of personality": The Big-Five factor structure. Journal of Personality and Social Psychology, 59(6), 1216-1229.

Gray, D.E. (2004). Doing Research in the Real World. Cornwall: Sage Publications.

Henningsen, D.D., \& Henningsen, M.L.M. (2013). Generating Ideas About the Uses of Brainstorming: Reconsidering the Losses and Gains of Brainstorming Groups Relative to Nominal Groups. Southern Communication Journal, 78(1), 42-55.

Heslin, P.A. (2009). Better than brainstorming? Potential contextual boundary conditions to brainwriting for idea generation in organizations. Journal of Occupational and Organizational Psychology, 82, $129-145$.

Hoff, E., Carlsson, I.M., \& Smith, G.J.W. (2012). Personality. In M.D. Mumford (Ed.), Handbook of organizational creativity (1st ed., pp. 241-270). Boston, Massachusetts, Amsterdam: Elsevier/Academic Press.

Hülsheger, U.R., Anderson, N., \& Salgado, J.F. (2009). Team-level predictors of innovation at work: A comprehensive meta-analysis spanning three decades of research. Journal of Applied Psychology, 94(5), 1128-1145.

John, O.P., \& Srivastava, S. (2001). The Big Five Trait Taxonomy: History, Measurement, and Theoretical Perspectives. In L.A. Pervin \& O.P. John (Eds.), Handbook of personality: Theory and research (2nd ed., pp. 102-138). New York: The Guilford Press.

Johnson, J.A. (2014). Measuring thirty facets of the Five Factor Model with a 120-item public domain inventory: Development of the IPIP-NEO-120. Journal of Research in Personality, 51, 78-89.

Jung, C.G. (1921, reprinted 2017). Psychological types. Routledge classics. Abingdon, Oxon, New York, NY: Routledge.

Jung, J.H., Lee, Y., \& Karsten, R. (2012). The Moderating Effect of Extraversion-Introversion Differences on Group Idea Generation Performance. Small Group Research, 43(1), 30-49.

Kasof, J. (1997). Creativity and Breadth of Attention. Creativity Research Journal, 10(4), 303-315.

Kirk, R.E. (2013). Experimental design: Procedures for the behavioral sciences (4th ed.). Los Angeles, California: Sage Publications.

Korde, R. (2014). Hybrid Brainwriting: The efficacy of alternating between individual and group brainstorming and the effect of individual differences (Dissertation). University of Texas, Arlington.

Korde, R., \& Paulus, P.B. (2017). Alternating individual and group idea generation: Finding the elusive synergy. Journal of Experimental Social Psychology, 70, 177-190.

Kozlowski, S.W.J., \& Ilgen, D.R. (2006). Enhancing the Effectiveness of Work Groups and Teams. Psychological Science in the Public Interest: A Journal of the American Psychological Society, 7(3), 77-124.

Laerd Statistics. (2015a). Paired-samples t-test using SPSS Statistics. Retrieved from https://statistics.laerd.com/

Laerd Statistics. (2015b). Two-way mixed ANOVA using SPSS Statistics. Retrieved from https://statistics.laerd.com/

Lamm, H., \& Trommsdorff, G. (1973). Group versus individual performance on tasks requiring ideational proficiency (brainstorming): A review. European Journal of Social Psychology, 3(4), 361-388. 
McCrae, R.R., \& John, O.P. (1992). An Introduction to the Five-Factor Model and Its Applications. Journal of Personality, 60(2), 175-215.

Mullen, B., Johnson, C., \& Salas, E. (1991). Productivity Loss in Brainstorming Groups: A MetaAnalytic Integration. Basic and Applied Social Psychology, 12(1), 3-23.

Mumford, M.D., Hester, K.S., \& Robledo, I.C. (2012). Creativity in Organizations. In M.D. Mumford (Ed.), Handbook of organizational creativity (1st ed., pp. 3-16). Amsterdam, Boston: Academic Press.

Osborn, A.F. (1957, reprinted 2013). Applied Imagination: Principles and Procedures of Creative Writing. Read Books Ltd.

Paulus, P.B. (2000). Groups, Teams, and Creativity: The Creative Potential of Idea-generating Groups. Applied Psychology: An International Review, 49(2), 237-262.

Paulus, P.B., Dzindolet, M., \& Kohn, N.W. (2012). Collaborative Creativity-Group Creativity and Team Innovation. In M.D. Mumford (Ed.), Handbook of organizational creativity (1st ed., pp. 327357). Amsterdam, Boston: Academic Press.

Paulus, P.B., Korde, R.M., Dickson, J.J., Carmeli, A., \& Cohen-Meitar, R. (2015). Asynchronous Brainstorming in an Industrial Setting. Human Factors: The Journal of the Human Factors and Ergonomics Society, 57(6), 1076-1094.

Paulus, P.B., Larey, T.S., \& Dzindolet, M.T. (2000). Creativity in groups and teams. In M. Turner (Ed.), Groups at work: Advances in theory and research (pp. 319-338). Hillsdale, NJ: Erlbaum.

Paulus, P.B., Larey, T.S., \& Ortega, A.H. (1995). Performance and Perceptions of Brainstormers in an Organizational Setting. Basic and Applied Social Psychology, $17(1$ \& 2), 249-265.

Paulus, P.B., \& Yang, H-C. (2000). Idea Generation in Groups: A Basis for Creativity in Organizations. Organizational Behavior and Human Decision Processes, 82(1), 76-87.

Pervin, L.A., \& Cervone, D. (2010). Personality: Theory and research (11th ed.). Hoboken, NJ: John Wiley \& Sons.

Quinlan, C. (2011). Business research methods. Andover: Cengage Learning.

Rietzschel, E.F., Nijstad, B.A., \& Stroebe, W. (2006). Productivity is not enough: A comparison of interactive and nominal brainstorming groups on idea generation and selection. Journal of Experimental Social Psychology, 42(2), 244-251.

Sani, F., \& Todman, J.B. (2008). The Nature of Psychology Experiments (II): Validity. In F. Sani \& J.B. Todman (Eds.), Experimental design and statistics for psychology: A first course (pp. 18-38). Malden, MA: Blackwell Publications.

Sapsford, R. (2007). Survey research (2nd ed.). London, Thousand Oaks, California: Sage Publications.

Sutton, R.I., \& Hargadon, A. (1996). Brainstorming Groups in Context: Effectiveness in a Product Design Firm. Administrative Science Quarterly, 41(4), 685-718.

Tang, M. (2016). Creativity and Innovation: Basic Concepts and Approaches. In M. Tang \& C.H. Werner (Eds.), Handbook of the Management of Creativity and Innovation (pp. 3-32). Singapore: World Scientific.

Taylor, D.W., Berry, P.C., \& Block, C.H. (1958). Does Group Participation When Using Brainstorming Facilitate or Inhibit Creative Thinking? Administrative Science Quarterly, 3(1), 23.

Tjosvold, D., West, M.A., \& Smith, K.G. (2003). Fundamentals of Organizational Effectiveness. In D. Tjosvold, M.A. West, \& K.G. Smith (Eds.), International Handbook of Organizational Teamwork and Co-operative Working (pp. 3-8). Chichester: Wiley.

Valacich, J.S., Dennis, A.R., \& Nunamaker, J.F. (1992). Group size and anonymity effects on computermediated idea generation. Small Group Research, 23(1), 49-73.

VanGundy, A.B. (1984). Brainwriting for new product ideas: An alternative to brainstorming. Journal of Consumer Marketing, 1(2), 67-74.

Watson, D., \& Clark, L.A. (2007). Extraversion and Its Positive Emotional Core. In R. Hogan \& J. Johnson (Eds.), Handbook of personality psychology (pp. 767-793). Amsterdam: Elsevier.

West, M.A. (2002). Sparkling Fountains or Stagnant Ponds: An Integrative Model of Creativity and Innovation Implementation in Work Groups. Applied Psychology: An International Review, $51(3), 355-424$. 